Pathophysiology of Haemostasis and Thrombosis
Pathophysiol Haemost Thromb 2002;32:190-193

DOI: $10.1159 / 000070426$
Received: October 16, 2002

Accepted after revision: December 18, 2002

\title{
Plugged-Percutaneous Liver Biopsy in Patients with Impaired Coagulation and Ascites
}

\author{
Pieter W. Kamphuisen ${ }^{a}$ Tjeerd G. Wiersma ${ }^{b}$ Chris J.J. Mulder ${ }^{c}$ \\ Richard A. de Vries ${ }^{a, c}$
}

Departments of a Internal Medicine, ${ }^{b}$ Radiology and ${ }^{\mathrm{c}}$ Gastroenterology, Rijnstate Hospital,

Arnhem, The Netherlands

\author{
Key Words \\ Liver disease · Coagulation abnormalities · Ascites · \\ Liver biopsy, plugged-percutaneous
}

\begin{abstract}
In liver cirrhosis coagulation is impaired due to decreased synthesis of vitamin K-dependent and vitamin $\mathrm{K}$-independent coagulation factors. In such patients routine liver biopsy is contraindicated due to the increased risk of bleeding. Treatment with recombinant factor VIla or fresh frozen plasma reduces the complication rate of liver biopsy, but both have disadvantages. In this observational study, we evaluated the safety and efficacy of plugged-percutaneous liver biopsy in 36 patients with ascites $(n=9)$, impaired coagulation $(n=22)$, or both $(n=$ 5) due to severe chronic liver disease. Among patients with clotting disorders, mean prothrombin time was $16.3 \mathrm{~s}$ (range 11.4-20.3) and the mean platelet count was $53 \times 109 /$ (range 19-153). Plugged-percutaneous liver biopsy was in none of the cases associated with bleeding complications (95\% confidence interval 0-0.097). All biopsies were adequate for histological interpretation and therefore diagnostically successful. In our experi-
\end{abstract}

\section{KARGER}

Fax +41613061234

E-Mail karger@karger.ch

www.karger.com

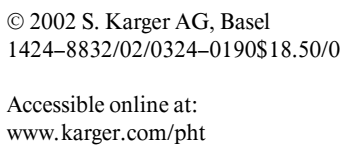

ence, plugged-percutaneous liver biopsy seems a safe and reliable method in patients with chronic liver disease associated with impaired coagulation and/or ascites needing histological evaluation.

Copyright $@ 2002$ S. Karger AG, Basel

\section{Introduction}

Liver biopsy is in general a safe and reliable method in the diagnostic work-up of hepatic disease. Since mortality $(0.01 \%)$ and morbidity $(0.2 \%)$ are relatively low, this procedure is widely used $[1,2]$. Severe haemorrhage is the most common serious complication of liver biopsy as a result of damage of the arterial tree or a distended portal vein radicle. McGill et al. [3] found that among 9,212 liver biopsies $0.11 \%$ were complicated by fatal and $0.24 \%$ by non-fatal haemorrhage.

In patients with chronic liver disease coagulation is impaired due to a decreased synthesis of vitamin Kdependent and vitamin $\mathrm{K}$-independent coagulation factors, and this reduction is most pronounced for factor VII. A deficiency of factor VII results in an increased risk of bleeding complications, since factor VII initiates coagula- 


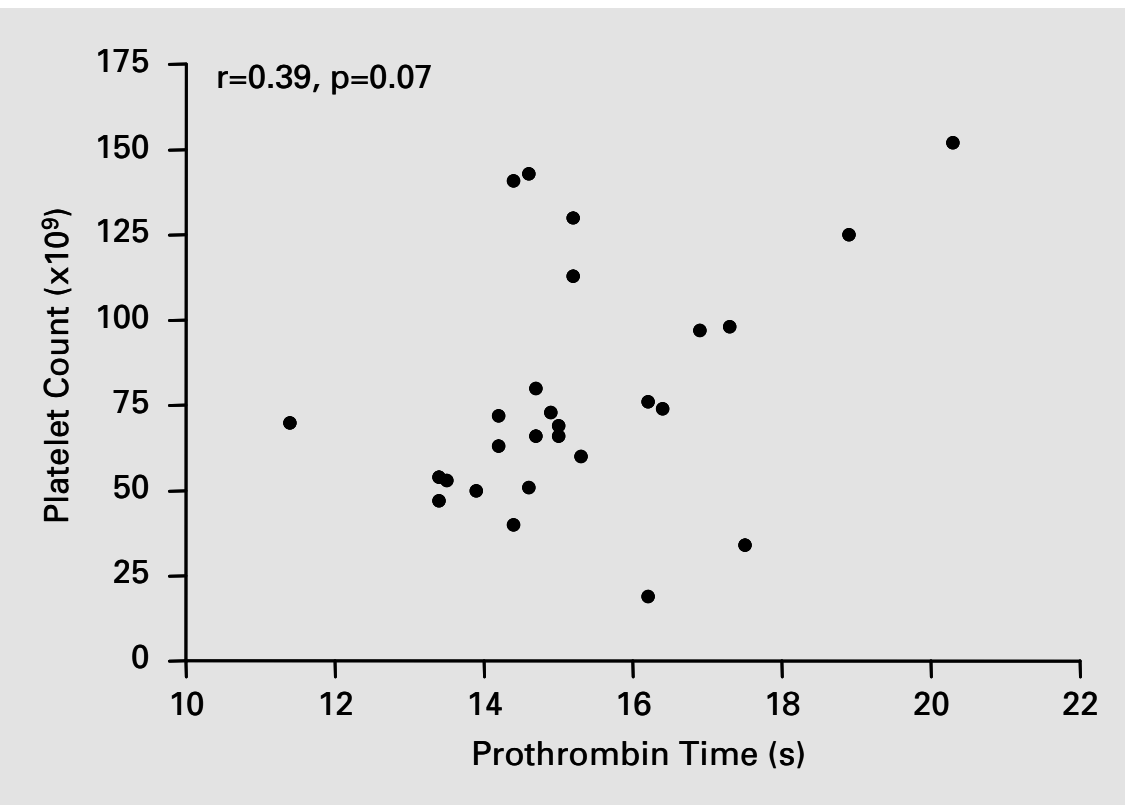

Fig. 1. Prothrombin time and platelet count of the patients with coagulation disorders.

Table 2. Histological diagnosis (n)

\begin{tabular}{lr}
\hline All patients & 36 \\
Cirrhosis & 18 \\
Malignancy & 8 \\
Chronic hepatitis & 5 \\
Peliosis hepatitis & 1 \\
Venoocclusive disease & 2 \\
Primary biliary cirrhosis & 1 \\
Haemangioma & 1 \\
\hline
\end{tabular}

\section{Discussion}

This small observational study suggests that ultrasound-guided plugged-percutaneous liver biopsy is a safe and reliable method in patients with moderate coagulation disorders and/or ascites. Furthermore, this method is relatively easy to perform and yields adequate liver biopsies.

Since the paper by Riley et al. [6] in 1984, percutaneous liver biopsy with plugging of the needle track can be considered as an alternative method for obtaining liver tissue in patients with clotting disorders. It is easier to perform and much quicker than transjugular liver biopsy, which also seems to be safe, but is more time-consuming and more difficult to perform. In addition, biopsies ob- tained by the transjugular method are on average smaller than in the case of percutaneous liver biopsy, as was shown by Sawyer et al. [7]. Transjugular and plugged-percutaneous liver biopsies are associated with a low incidence of complications in patients with clotting disorders, although $3.5 \%$ of the patients experienced a bleeding complication after plugged-percutaneous liver biopsy, whereas no haemorrhage was noted in patients with transjugular liver biopsy. In 100 consecutive patients presenting with liver disease and moderately severe coagulation defects, plugged-percutaneous liver biopsy did not lead to serious bleeding complications [7]. Our findings are in accordance with these data.

Like coagulation disorders, ascites is considered as a contraindication for percutaneous liver biopsy, due to increased bleeding risk, infection or postbiopsy ascitic leakage [5]. Two studies showed that CT- or ultrasoundguided liver biopsy was not associated with an increased complication rate $[8,9]$. In our study no liver biopsy-related bleeding or inadequate liver tissue samples using ultrasound-guided plugged-percutaneous liver biopsy in patients with ascites were found. Also in patients with both moderate coagulopathy and ascites no complications have been recognized.

There was no association between prothrombin time and platelet count in patients with clotting disorders, and also no correlation between platelet count and bleeding time, in accordance with other reports [10, 11]. Measure- 
ment of the bleeding time does not appear to provide additional information concerning the risk of bleeding [10].

Our study has several drawbacks. The expected bleeding rate in liver biopsy is $0.24 \%$; our sample size is, therefore, probably too small (upper confidence interval 0.097) to safely exclude the possibility of bleeding complications. Furthermore, this was an observational study without a control group. Theoretically, percutaneous liver biopsy performed under ultrasound guidance by injection of a polyvinyl foam (Ivalon) in the needle track is an option in patients with moderate coagulation abnormalities. This plugging of the needle track will induce mechanical occlusion and local haemostasis, and seems to overcome the increased risk of bleeding in mild coagulopathy or ascites. Based on the findings in earlier reports, plugged-percutaneous liver biopsy is recommended in patients with liver disease and moderate coagulopathy, i.e. prothrombin time prolongation $<6 \mathrm{~s}$ or platelet count $20-80 \times 10^{9} / 1$ [5-7]. To our experience, this method also seems safe in ascites, and even in patients with the combination of coagulopathy and ascites.
Recently it has been shown that in patients with liver cirrhosis treatment with recombinant factor VII (rFVIIa) corrects prolonged prothrombin time [12] and reduces complication rate in laparoscopic liver biopsy [12]. In liver cirrhosis factor VII levels are markedly reduced and rFVIIa probably restores thrombin generation [13]. The main disadvantage of this new treatment modality is its high cost. Infusion with fresh frozen plasma is another good alternative in liver cirrhosis, but is associated with the risk of potentially transmitting blood-borne infections. These two treatment modalities might be indicated in patients with more severe coagulopathy [12]. Percutaneous liver biopsy with plugging of the needle track seems at least as safe as rFVIIa in patients with moderate clotting disorders, and is much cheaper.

In conclusion, in our experience ultrasound-guided plugged-percutaneous liver biopsy can be successfully and safely undertaken in patients with moderate coagulation disorders, ascites or both conditions.

\section{References}

1 Lindner H: Grenzen und Gefahren der perkutanen Leberbiopsie mit der Menghini-Nadel: Erfahrungen bei 80000 Leberbiopsien. Dtsch Med Wochenschr 1967;92:1751.

2 Zamcheck N, Klausenstock O: Liver biopsy. 11. The risk of needle biopsy. N Engl J Med 1953;1062.

3 McGill DB, Rakela J, Zinsmeister AR, Ott BJ: A 21-year experience with major hemorrhage after percutaneous liver biopsy. Gastroenterology 1990;99:1396-1400.

4 Perrault J, McGill DB, Ott BJ, Taylor WF: Liver biopsy: Complications in 1000 inpatients and outpatients. Gastroenterology 1978;74: 103-106.

5 Murphy FB, Barefield KP, Steinberg HV, Bernardino ME: CT- or sonography-guided biopsy of the liver in the presence of ascites: Frequency of complications. AJR Am J Roentgenol 1988; 151:485-486.
6 Riley SA, Irving HC, Axon ATR, Ellis WR, Lintott DJ, Losowsky MS: Percutaneous liver biopsy with plugging of the needle track: A safe method for use in patients with impaired coagulation. Lancet 1984;ii:436.

7 Sawyer AM, McCormick PA, Tennyson GS, Chin J, Dick R, Scheuer PJ, et al: A comparison of transjugular and plugged-percutaneous liver biopsy in patients with impaired coagulation. $\mathbf{J}$ Hepatol 1993;17:81-85.

8 Tobin MV, Gilmore IT: Plugged liver biopsy in patients with impaired coagulation. Dig Dis Sci 1989;34:13-15.

9 Little AF, Ferris JV, Dodd GD III, Baron RL: Image guided percutaneous hepatic biopsy: Effect of ascites on the complication rate. Radiology 1996;199:79-83.
10 Burroughs AK, McCormick PA, Sprengers D: Assessment of bleeding risk in chronic liver disease. Fibrinolysis 1988;2(suppl 3):56-60.

11 Mannucci PM, Vincenti V, Vianello L, Cattaneo M, Alberca I, Coccato MP, Faioni E, Mari $\mathrm{D}$ : Controlled trial of desmopressin in liver cirrhosis and other conditions associated with a prolonged bleeding time. Blood 1986;67:11481153.

12 Jeffers L, Chalasani N, Balart L, Pyrsopoulos N, Erhardtsen E: Safety and efficacy of recombinant factor VIIa in patients with liver disease undergoing laparoscopic liver biopsy. Gastroenterology 2002;123/1:118-126.

13 Van 't Veer C, Golden NJ, Mann KG: Inhibition of thrombin generation by the zymogen factor VII: Implications for the treatment of hemophilia A by factor VIIa. Blood 2000;95: 1330-1335. 